\title{
EXÓRDIO DO SERMÃO DE SANTO ANTÔNIO PREGADO POR ANTÔNIO VIEIRA
}

o peixe como metáfora do homem e o sal que já não salga

\section{EXORDIUM OF THE SERMON OF SAINT ANTHONY PREACHED BY ANTÔNIO VIEIRA}

the fish as a metaphor for men and the salt that no longer salts

\section{RESUMO}

O Sermão de Santo Antônio, pregado em São Luís do Maranhão no ano de 1964 pelo Padre Antônio Vieira em homenagem a Santo Antônio e em crítica da corrupção humana, é um dos mais importantes sermões do influente jesuíta, pois, na filosofia cristã, ressignifica conceitos centrais (o valor da ação animal) e aprofunda tópicos tradicionais (livre arbítrio e conversão). O exórdio desse sermão é seu capítulo de maior importância; nele, Vieira apresenta o conceito predical que guiará seu discurso "vós sois o sal da terra" - por meio do qual estabelece a questão que desenvolverá a pregação: o problema de haver tantos pregadores e a terra se ver tão corrompida. Além disso, no exórdio o próprio modelo do sermão, uma alegoria, e seu personagem principal, Santo Antônio, são justificados. Esta resenha busca contextualizar, criticar e explanar tal exórdio.

Palavras-chave: Sermão. Santo Antônio. Antônio Vieira. Sal da Terra.

\begin{abstract}
The Sermon of St. Anthony, preached in São Luís do Maranhão in 1654 by Father Antônio Vieira in homage to St. Anthony and in critique of human corruption, is one of the most important sermons of the influential Jesuit, because, in the context of Christian philosophy, it redefines central concepts (the value of animal action) and deepens traditional topics (free will and conversion). The chapter of greatest importance in this sermon is its Exordium, in which Vieira presents the predical concept that will guide his discourse - "you are the salt of the earth" -, and through which the author will establish the question to be developed: the problem of there being so many preachers and the earth still be so corrupted. Also, in the Exordium, the model of the sermon itself, an allegory, and its main character, St. Anthony, are justified. This review aims to criticize, contextualize and explains this exordium.
\end{abstract}

Keywords: Sermon. Saint Anthony. Antônio Vieira. Salt of the Earth.

\footnotetext{
${ }^{1}$ Graduando em Filosofia pela Universidade de Brasília (UnB) e graduando em Física pela Universidade Paulista (UNIP).

CV Lattes: http://lattes.cnpq.br/9397082137728466.

ORCID: https://orcid.org/0000-0002-1516-3473.
} 
O Sermão de Santo Antônio, também conhecido como Sermão de Santo Antônio aos Peixes, foi pregado por Antônio Vieira em São Luís do Maranhão no ano de 1654 (Brasil Colonial), especificamente no dia 13 de junho, escolhido por Vieira por ser dedicado, no calendário litúrgico católico, a Santo Antônio, santo que o pregador coloca como personagem principal de seu sermão.

Antônio Vieira era, no século XVII, um padre português da Igreja Católica Apostólica Romana, ordenado religioso da Companhia de Jesus. Foi influente orador em Portugal e suas colônias, onde ganhou notoriedade por contestar a perseguição de sua igreja aos cristãosnovos (nascidos judeus convertidos ao cristianismo), e tornou-se figura polêmica dentre os clérigos por negar diversas decisões da Santa Inquisição Católica de seu período.

O específico sermão foi pregado em um contexto de longo litígio entre Vieira, com suas posições favoráveis aos direitos individuais indígenas (não culturais), e os colonos portugueses, que faziam uso da mão de obra indígena de maneira escravista. Alguns dias após pregar tal sermão, Vieira embarcou, supostamente de forma sigilosa, da colônia para a metrópole (Portugal), visando a tratar com o rei Dom João IV das condições e possíveis proteções contra a escravidão destinadas aos indígenas colonizados.

O Sermão de Santo Antônio tem como característica do estilo de escrita o exacerbado uso da sátira e pontuados usos de ironia - tendo em vista a situação na qual Vieira o prega, fica nítida sua indignação para com a sociedade que o cerca, na qual a corrupção do homem, em um sentido bastante agostiniano do termo "corrupção" na tradição católica, não é exceção, mas, ao contrário, tornou-se normalidade.

O Sermão de Santo Antônio aos peixes não é pregado em formato dissertativo simples, sendo, efetivamente, uma alegoria. Em figuração alegórica, Vieira constrói, tendo Santo Antônio como personagem central, uma cena em que o santo estaria a pregar na Itália, precisamente em Arimino, contra os hereges; sendo o santo altamente qualificado (um doutor da igreja), estava a colher frutos de suas pregações - tanto que a população, originalmente de maioria herege, levantara-se contra ele e sua prática evangelizadora polemista (crítica ao não evangelho). Na alegoria, Santo Antônio, impossibilitado pelo próprio ânimo de desistir da doutrina, mas não mais conseguindo pregar aos homens daquela cidade, volta-se aos peixes, pregando na praia para tais animais. Os peixes são, no sermão, uma metáfora da humanidade, escolhidos para tal figuração pois não podem se converter - "Mas esta dor é tão ordinária [ao evangelizador], que já pelo costume quase se não sente" (VIEIRA, 1654). A ironia se dá, então, pela troca dos homens pelos peixes como público do sermão: os 
homens teriam sido dotados, em sua criação, de todas as virtuosas características para que buscassem seguir verdadeiramente o sumo-bem; os peixes, porém, são impossibilitados de tal ação por sua natureza - mesmo assim, parecia ao Santo Antônio do texto de Vieira não haver grande diferença entre pregar aos homens e pregar aos peixes.

Os peixes, como sátira do homem, versificam portanto os vícios e as imperfeições humanas ao longo de todo o texto; porém, sua simples escolha destaca um vício em específico como base de todos os outros: o da não colaboração para a verdadeira conversão, isto é, o da a recusa ao abandono do viver corrompido. Ao longo do sermão, Vieira, por meio do personagem que constrói de Santo Antônio, para ainda mais depreciar as ações humanas, demonstra que os peixes ao menos não desagradam a Deus, pois cumprem de maneira perfeita seu papel como animais, de nível ontológico inferior ao humano em criação, enquanto o humano em muito desagrada a Deus, por seu uso corrompido do livre arbítrio.

O exórdio do sermão, seu Capítulo I, não é apenas um exórdio à pregação por vir no decorrer do texto, mas é também um exórdio à própria humanidade, isto é, uma introdução ao humano, constando de sua possibilidade e até função, em vistas teológicas e em contrapartida à real situação na qual se encontrava. Além de metaforizar, no objetivo de sátira, os homens como peixes, o exórdio estabelece outra questão que baseará todo o sermão: o trato do conceito predicável de vós sois o sal da Terra.

Vós sois o sal da Terra é uma passagem bíblica exposta no Evangelho segundo Mateus, Capítulo V, versículo 13. Ser o sal da Terra é uma de duas características, mas também funções, humanas que Mateus apresenta no Capítulo V; a segunda é ser a luz do mundo (Mateus, V, 14).

No primeiro parágrafo do exórdio e partindo do Evangelho de Mateus, Vieira cita o conceito predical de vós sois o sal da Terra de maneira a reforçar essa função humana, declarando que Cristo assim o havia definido aos pregadores. Dessa maneira, todo homem tem potencial de ser sal da Terra, conforme o Evangelho segundo Mateus, porém aqueles que o são, especificamente, são os pregadores. Assim, o dever dos pregadores é que "façam na terra o que faz o sal" (VIEIRA, 1654). E o que faz o sal? "O efeito do sal é impedir a corrupção", afirma Vieira. Logo, cabe ao pregador manter fora da corrupção os virtuosos e retirar dela os corrompidos.

É importante compreender que uma leitura adequada do conceito de corrupção nesse texto de Vieira é possível por meio da concepção de Santo Agostinho, segundo a qual corrupto é aquele que, em uso de seu livre arbítrio, opta por não buscar o 
sumo-bem, dirigindo-se aos bem mutáveis, isto é, carnais e materiais (AGOSTINHO, De Libero Arbitrio, Cap. XX, Livro II). A corrupção a que se refere Vieira é uma corrupção da alma, no sentido cristão, não do indivíduo social, no sentido moral, político ou legal.

Ainda no primeiro parágrafo, Vieira levanta a grande problemática de seu sermão: havendo tantos pregadores na terra com função de impedir a corrupção, como a terra se encontra tão corrupta? São traçadas, então, as duas propostas de resposta para tal problemática, em forma metafórica, novamente comparando-se o pregador ao sal: "ou é porque o sal não salga, ou porque a terra se não deixa salgar” (VIEIRA, 1654).

A primeira possibilidade, o sal não salga, conota que aqueles que têm o ofício de evitar a corrupção - tal qual o sal, porém dos homens - não estão cumprindo seu dever, o que, descreve Vieira, pode ocorrer por três motivos: em primeiro lugar, os pregadores não estariam pregando a verdadeira doutrina; em segundo lugar, os pregadores estariam pregando algo e agindo divergentemente dele; em terceiro lugar, os pregadores estariam pregando a si e não a Cristo.

A segunda possibilidade, a terra se não deixa salgar, conota, por sua vez, a possibilidade de culpa não naquele que prega, mas naqueles que recebem a pregação. Vieira descreve também três possíveis desvios que estariam ocorrendo para tal caso ser verídico: em primeiro lugar, os ouvintes, mesmo recebendo verdadeira doutrina, não a quereriam receber; em segundo lugar, os ouvintes estariam querendo imitar os pregadores, ao invés de fazer o que eles pregam (essa segunda possibilidade de culpa dos ouvintes também engloba os pregadores, uma vez que é subentendido que o agir deles é corrompido, de modo que imitá-lo é corromper-se); em terceiro lugar, culpados seriam os ouvintes pois eles estariam servindo a seus próprios apetites, ao invés de servir a Cristo.

Citando novamente o Evangelho segundo Mateus, Vieira preocupa-se com a possibilidade de o sal não mais salgar, isto é, denotativamente, de os pregadores não mais cumprirem seu ofício de evitar a corrupção dos homens; segundo o Evangelho, teria dito Jesus que o pregador que faltar com a doutrina e como exemplo poderá ser dado como inútil. Não só inútil é aquele que prega e está corrompido; Vieira complementa que aquele que adultera a doutrina desafia Cristo - pior, aquele que fala a doutrina e age em desconformidade com ela é merecedor de desprezo.

Como Jesus não deixou resolução prática ao problema do sal que não salga, no terceiro parágrafo de seu texto Vieira expõe o porquê de escolher Santo Antônio para figurar como personagem. O Santo havia tomado para si uma resolução que 
Vieira adotaria também para seu próprio sermão. No quarto parágrafo inicia-se a alegoria, dando-se início à precitada resolução de Santo Antônio. A resolução do Santo aos problemas com o grupo para o qual pregava na Itália foi mudar seu auditório, para não precisar deixar seu ofício ou adulterar a doutrina, a qual, dada a resistência dos que a recebiam, não mais salgava, não mais evitava a corrupção da alma. O auditório escolhido por Santo Antônio teria sido a praia. "Já que me não querem ouvir os homens, ouçam-me os peixes", diz Santo Antônio na alegoria, enquanto glorifica Deus e os peixes se aglomeram para ouvir suas palavras.

No quinto parágrafo, é feita uma exaltação à atuação de Santo Antônio como destaque dentre os Santos e Doutores da Igreja, visto que, enquanto aos outros teria bastado evangelizar à terra, Santo Antônio - na impossibilidade de continuar pregando sobre a terra, pelo problema de lá suas palavras não serem mais como o sal dos homens, conforme deveriam ser - passa a pregar aos seres do mar, para que jamais pare de cumprir seu ofício.

Vieira justifica a maneira alegórica com que elabora seu sermão, não falando sobre Santo Antônio, mas vocalizando-o, como personagem ativo: segundo o autor, é mais favorável pregar como o santo que se homenageia do que pregar acerca dele.

Finalizando o exórdio de maneira dramática, seguindo o aclamado exemplo de Santo Antônio e tendo em vista sua indignação para com aquela sociedade que tentava retirar da corrupção (a exemplo de sua luta contra a escravização indígena praticada por tal sociedade), Padre Antônio Vieira declara que seu sermão também haveria de ser aos peixes, e somente aos peixes, que o escutariam nas praias próximas, aparentando estar farto do não aproveitamento de suas palavras por aqueles homens. 


\section{REFERÊNCIAS BIBLIOGRÁFICAS}

MARCONDES, Danilo. Santo Agostinho. In: Textos Básicos de Ética: de Platão a Foucault. Rio de Janeiro: Zahar, 2007.

VIEIRA, Antônio. Sermão de Santo Antônio [1654]. Belém: Universidade da Amazônia. Disponível em:

http://www.dominiopublico.gov.br/pesquisa/DetalheObraForm.do?select_action=\&co_obra=1 7349 . Acesso em: 05/03/2019. 